\title{
THE CUBAN GEOLOGICAL MAPPING, A CHALLENGE FOR THE FUTURE
}

Kenya E. Núñez Cambra Institute of Geology and Paleontology - Cuban Geological Survey // Cuban Geological Society 


\section{Content}

\section{Location}

History of Cuban Geological Mapping

- Second half of the XIX Century

- First half of the XX Century

- Second half of the XX Century

- XXI Century

Task for the future 
The Republic of Cuba is at the entrance to the Gulf of Mexico in the Northwestern of the Caribbean Sea

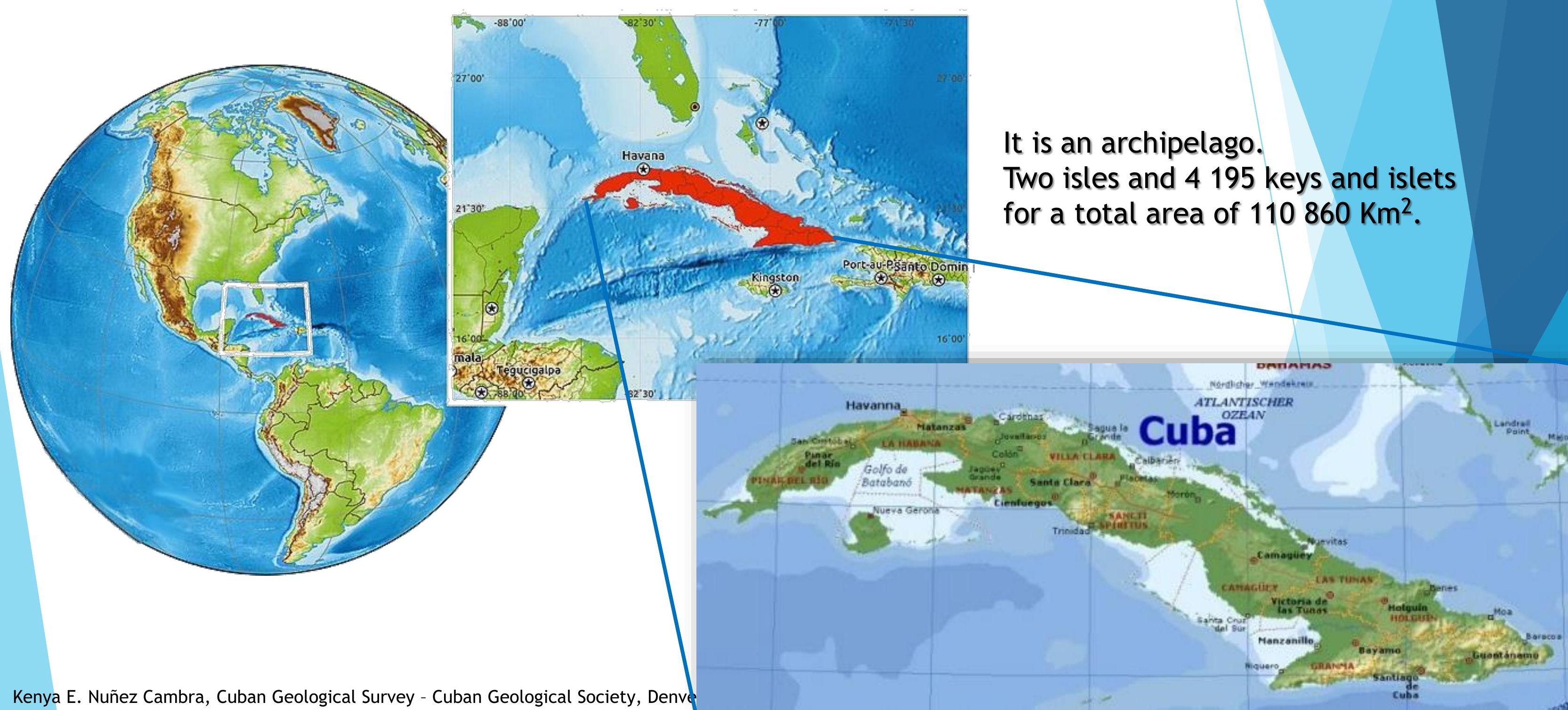




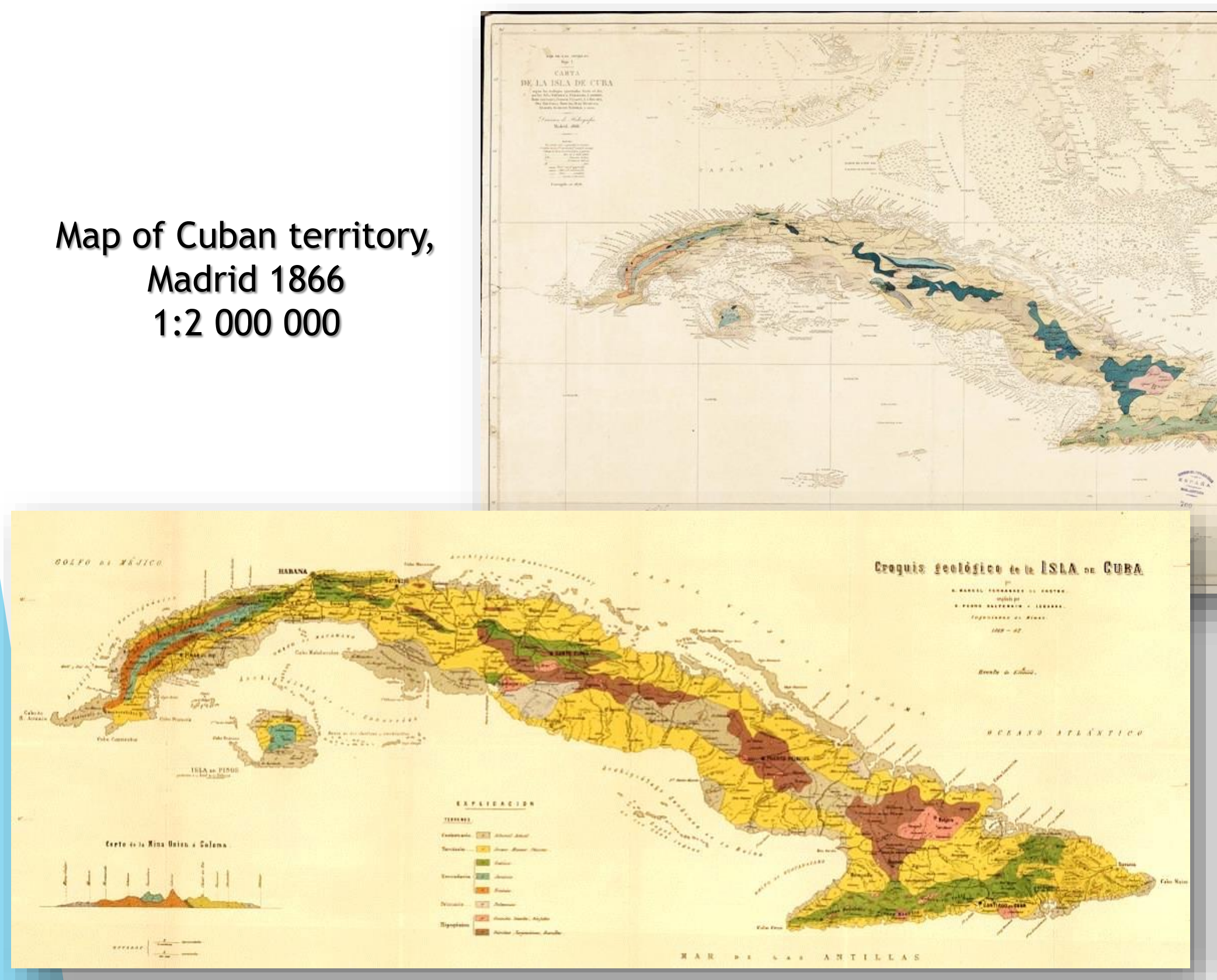

The first in Latin America

Geological Map of Cuba, Ramon Adan de Yarza 1895 


\section{Geological Sketch of Cuba}

scale 1:1000 000 1946 - 1955

Report of geological Reconnoissance of Cuba, C.W. Hayes, T.W. Vaughan and B.C. Spencer

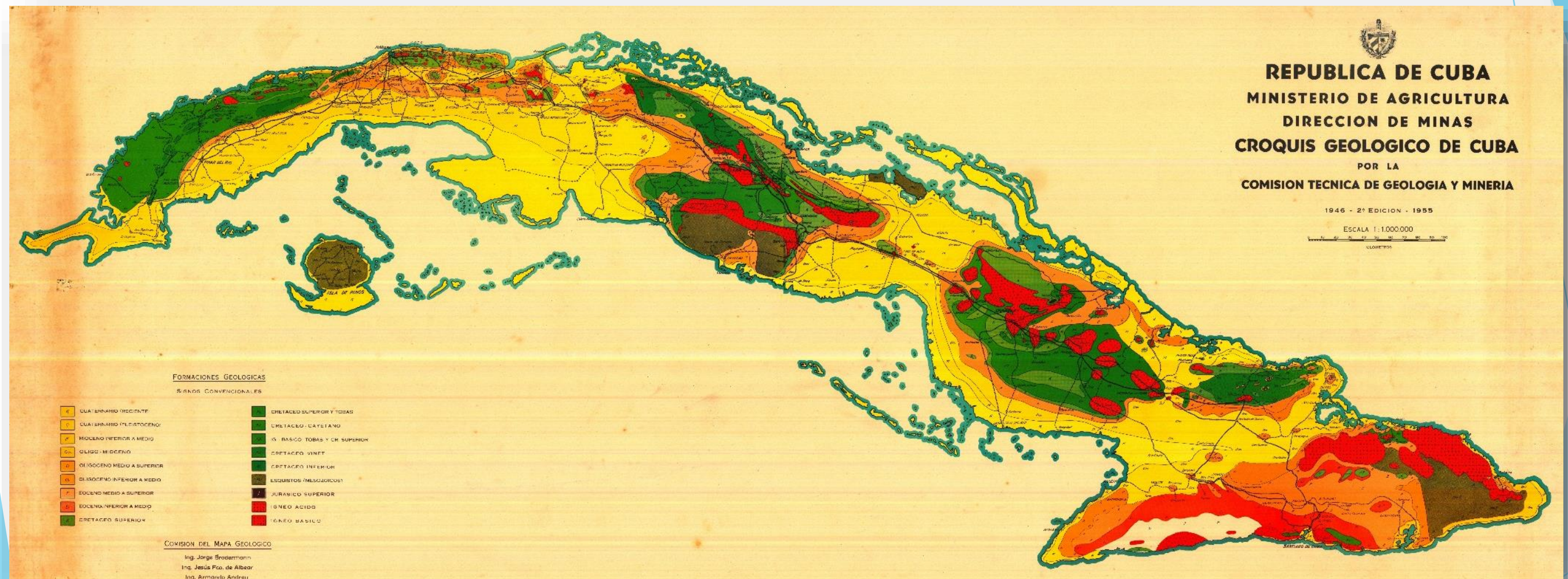

\section{Geology and Mine Technical Commition} Mine Dirección Agriculture Ministry Jorge Brödermann, Jesus Francisco de Albear and Armando Andrew
Geological, mine and others local tematic sketch by Antonio Calvache Dorado, Jorge Brödermann, Armando Andrew, Pedro J. Bermúdez, scale 1:1 000000. 


\section{Geological Map of Cuba}

scale 1:500 000 1985
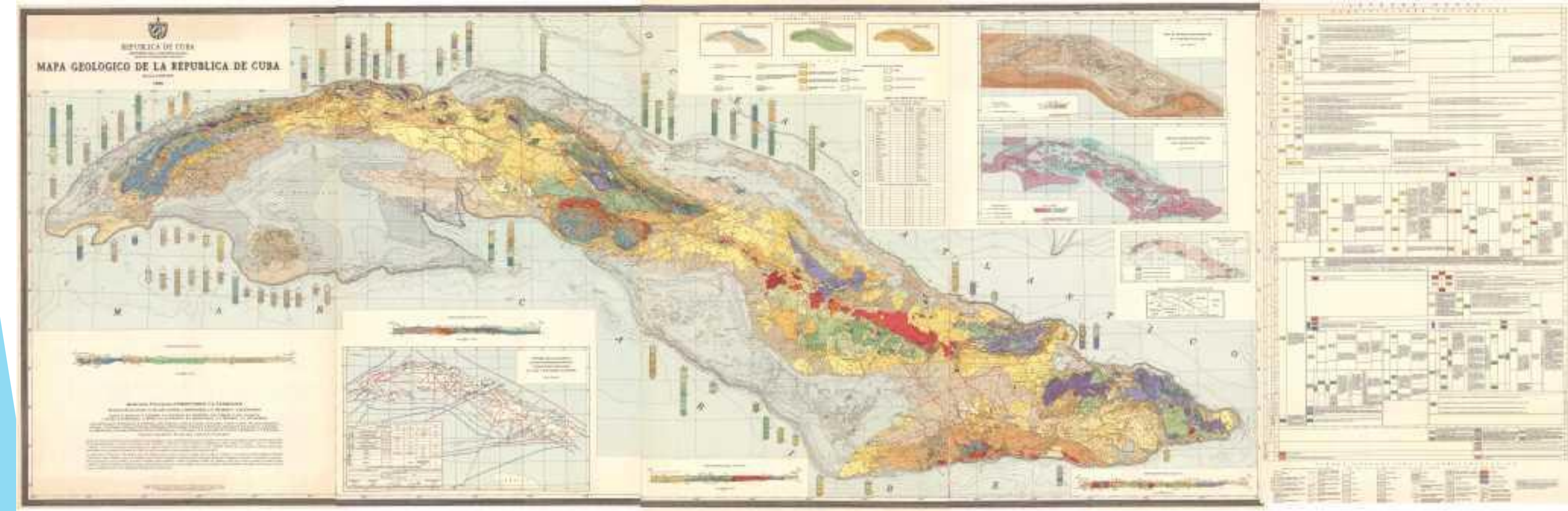

Geology Investigation Center (CIG)

E. Linares Cala, A.V Dovbnia, et al. 


\section{Geological Mapping works areas}

scale 1:250 000

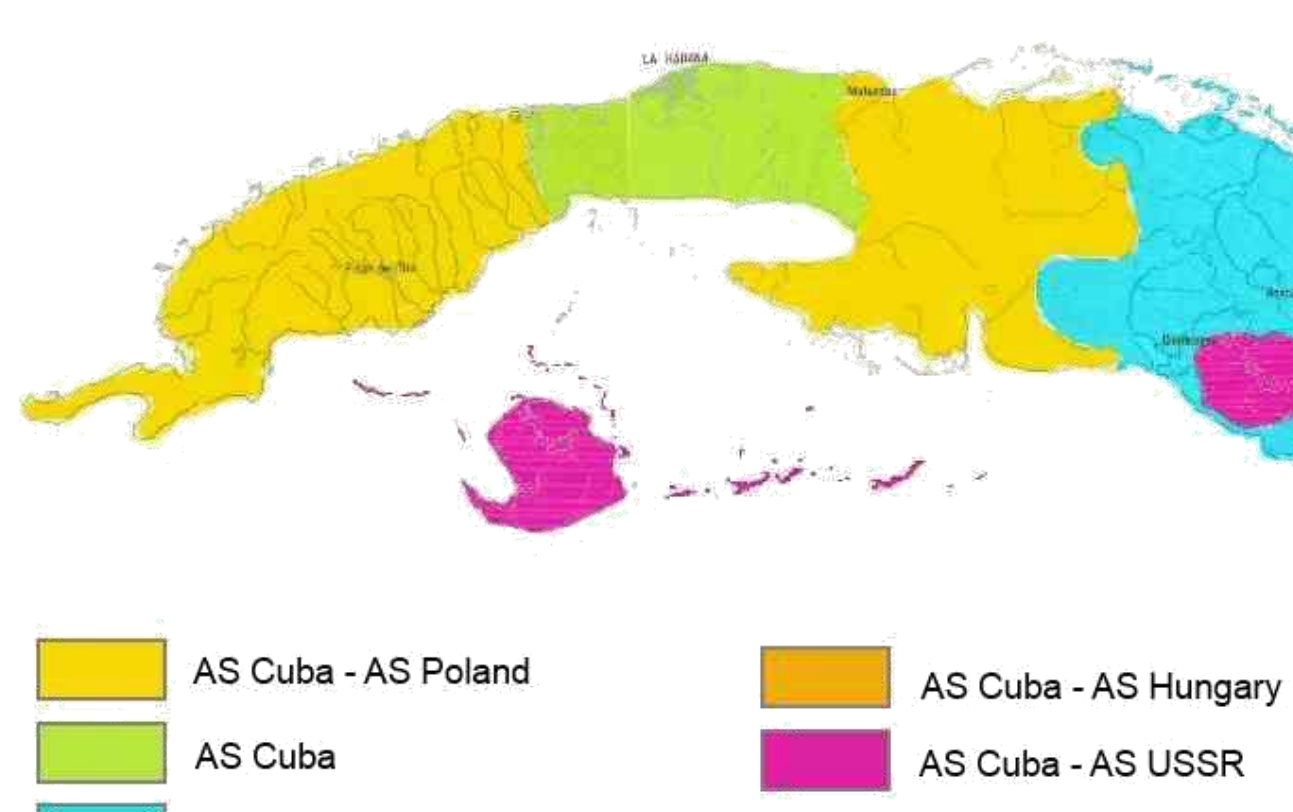

AS Cuba-AS Bulgaria

Under direction of scientific commission integrated by Academies of Sciences of Cuba and USSR. A consortium of the Academies of Sciences of Cuba, Bulgaria, Poland, Hungary, Rumania and the USSR (1969 - 1981) 


\section{Geological Map of Cuba}

- Second half of the XX Century scale 1:250 000

1988

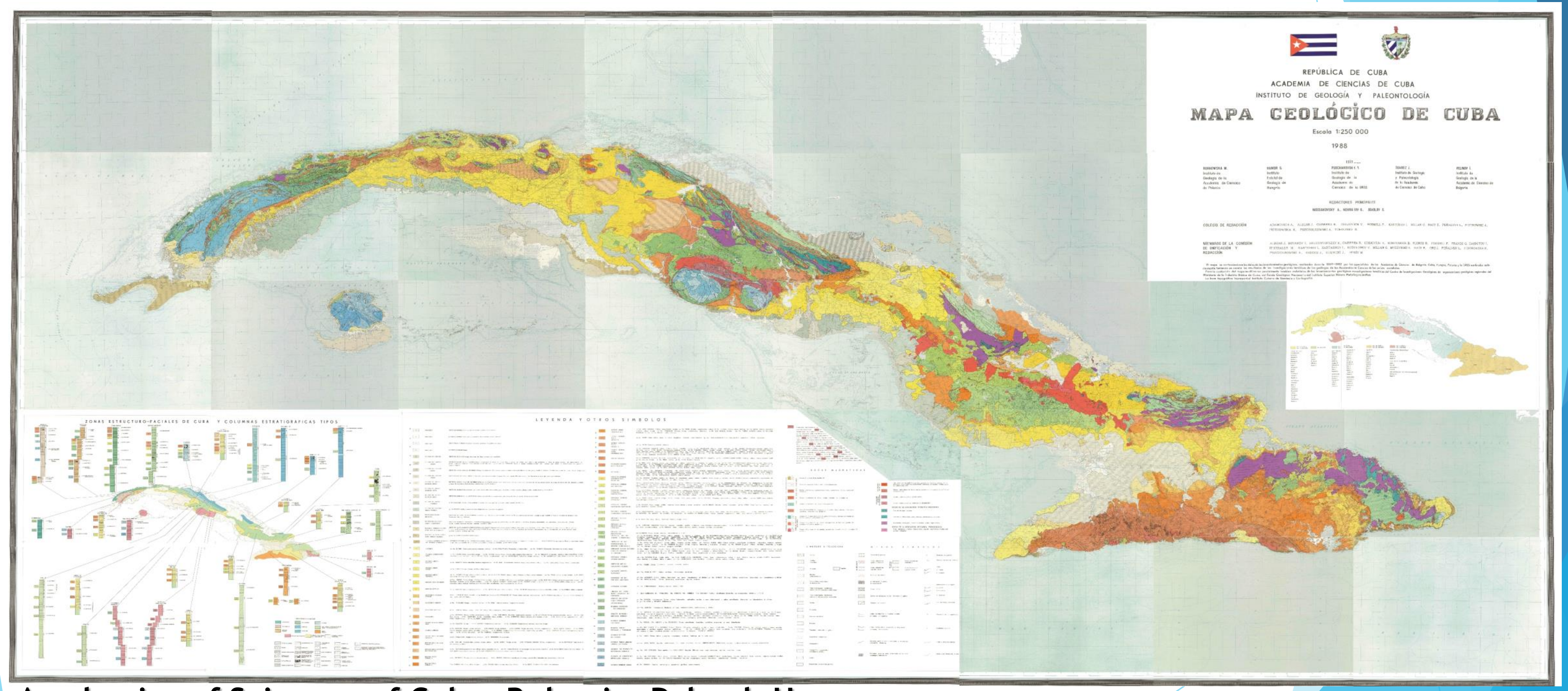

Academies of Sciences of Cuba, Bulgaria, Poland, Hungary, Rumania and the USSR (printer in USSR) 


\section{Tectonic Map of Cuba}

- Second half of the XX Century scale 1:500 000

\section{9}

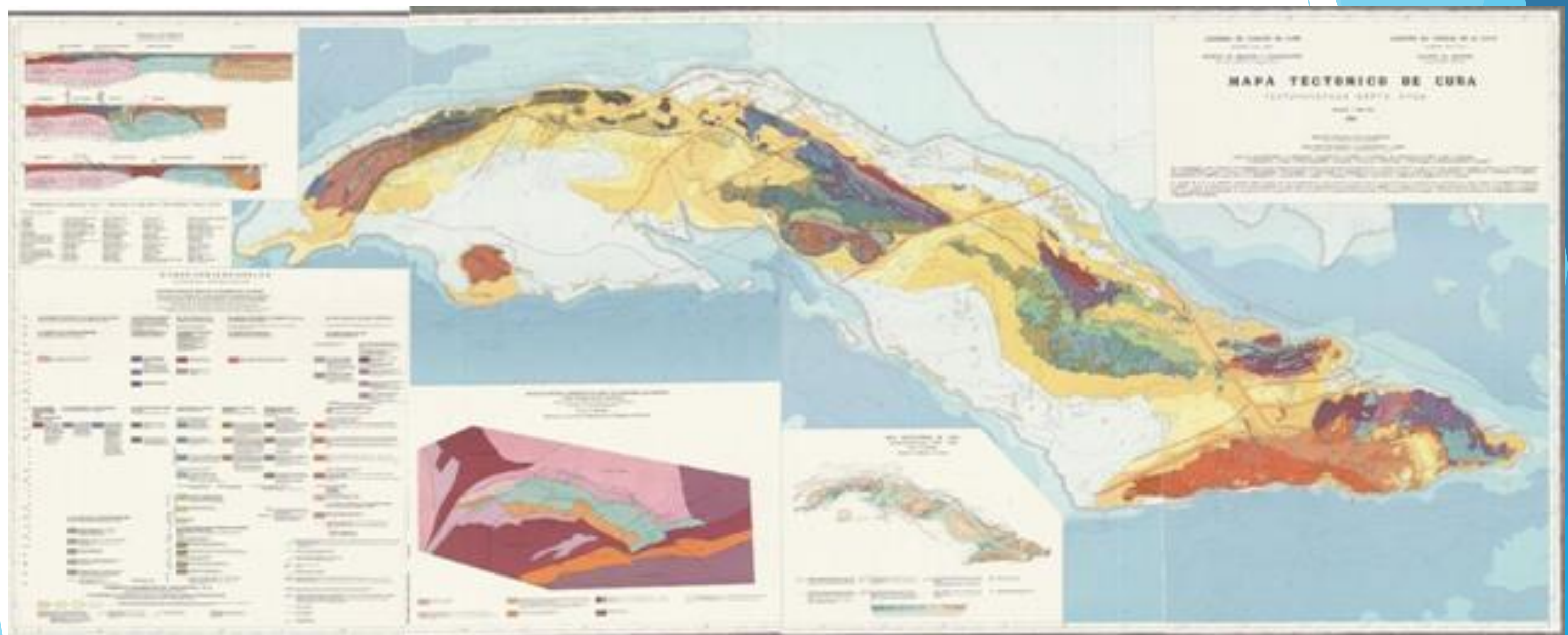

\section{Sciences Academies of USSR and Cuba}

Pushcharovsky, Yu., Mossakovsky, A., Nekrasov, G., Sokolov, S., M. Iturralde-Vinent, et al. 


\section{Complex Geological Mapping}

\section{escala 1:100 $000+1: 50000$}

\section{1-1994}

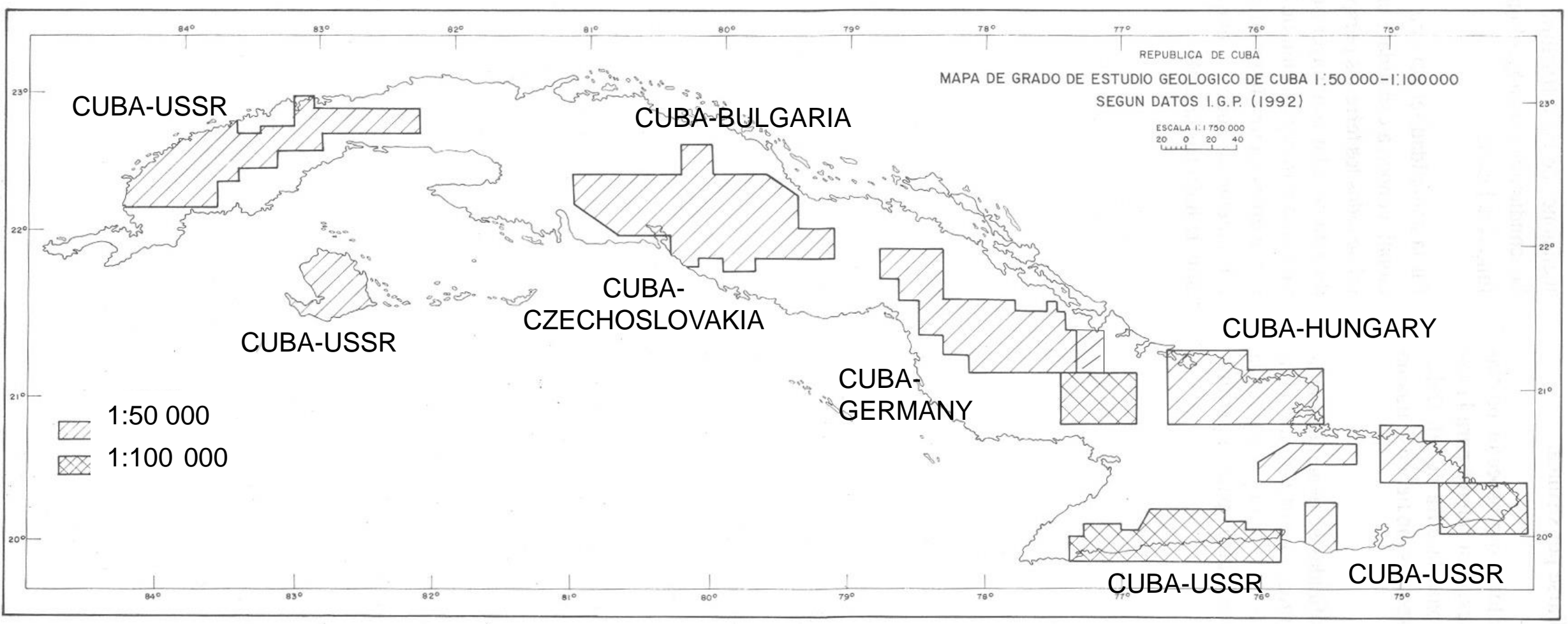

Only inside perspective areas of the country for localization and exploration of mineral resources. Applying geophysical and geochemical field methods in cooperation with the geological surveys of USSR, Germany, Hungary, Czechoslovakia and Bulgaria 


\section{Geological Map of Central Cuba} scale 1:50 000 1986-1989
- Second half of the XX Century

1:50 000 scale cartography covers only slightly more than $38 \%$ of the Cuban territory

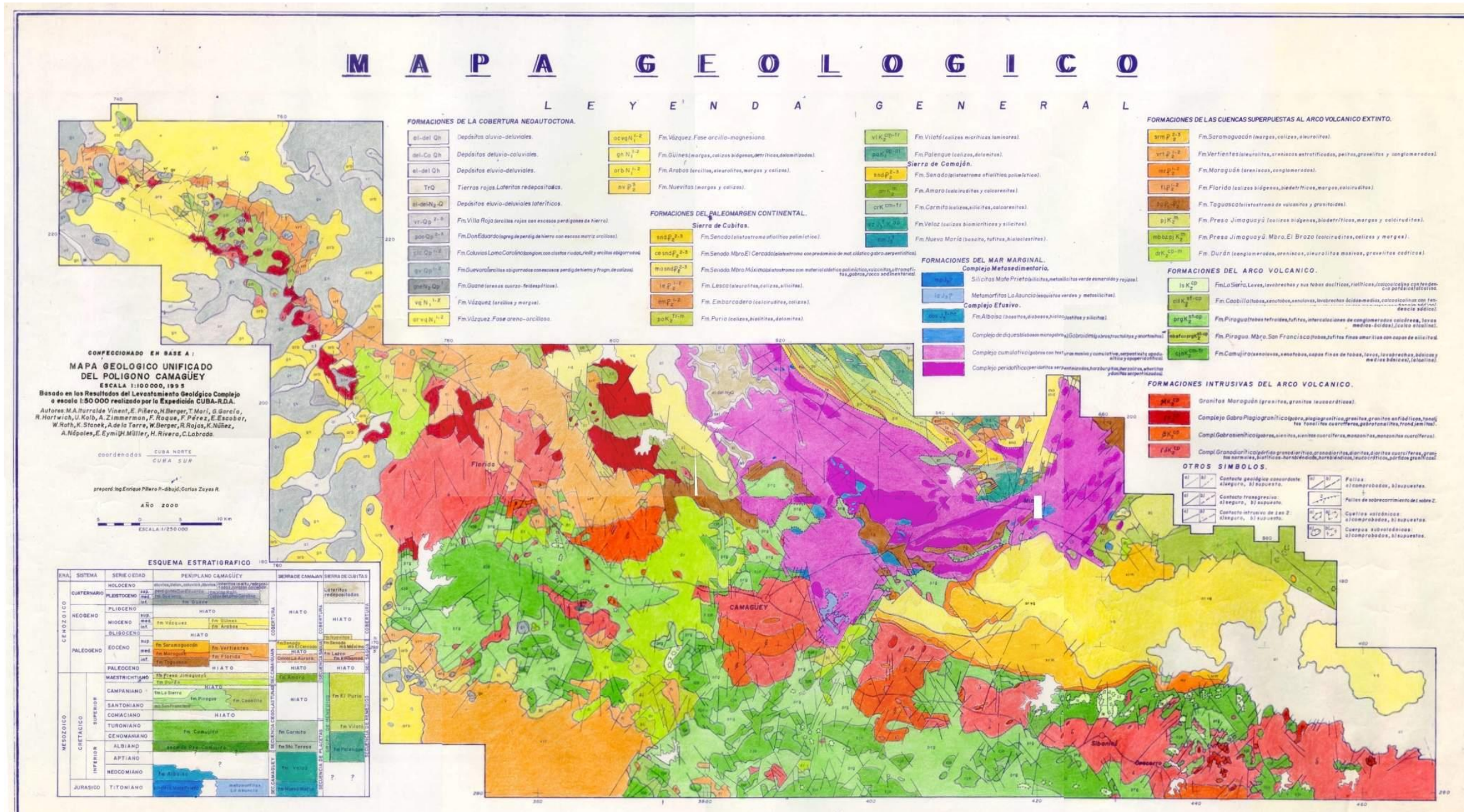




\section{Synthesis and compilation work}

scale 1:100 000

$1994-2005$

Digital Geological Map of Cuban Republic scale 1:100 000

2005-2007 unification and implementation in GIS 


\section{Applying Methodology}
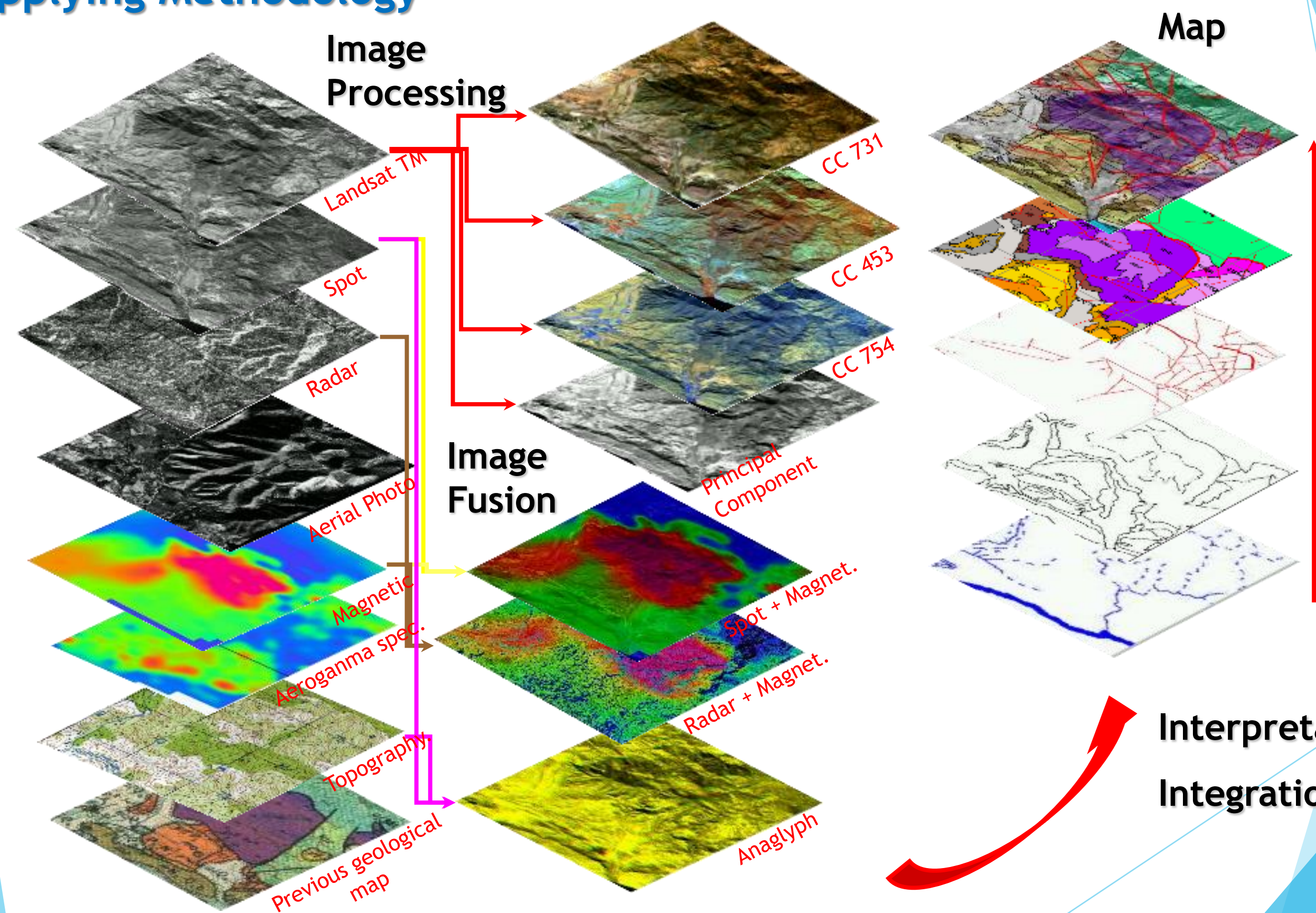

Kenya E. Nuñez Cambra, Cuban Geological Survey - Cuban Geological Society, Denver/2016

\section{Interpretation} Integration

( 
PMAPAS

Visualizador de Mapas 
- Complete the geological mapping scale 1:50 000, for $100 \%$ of the land and marine areas (2017-2030),

- Update the thematic maps (tectonic, geophysics, metallic and industrial minerals, active processes, etc.

- Contribute to OneGeology (1:1000 000),

Drepare GIS products,

- Elaborate 3D maps for specific regions,

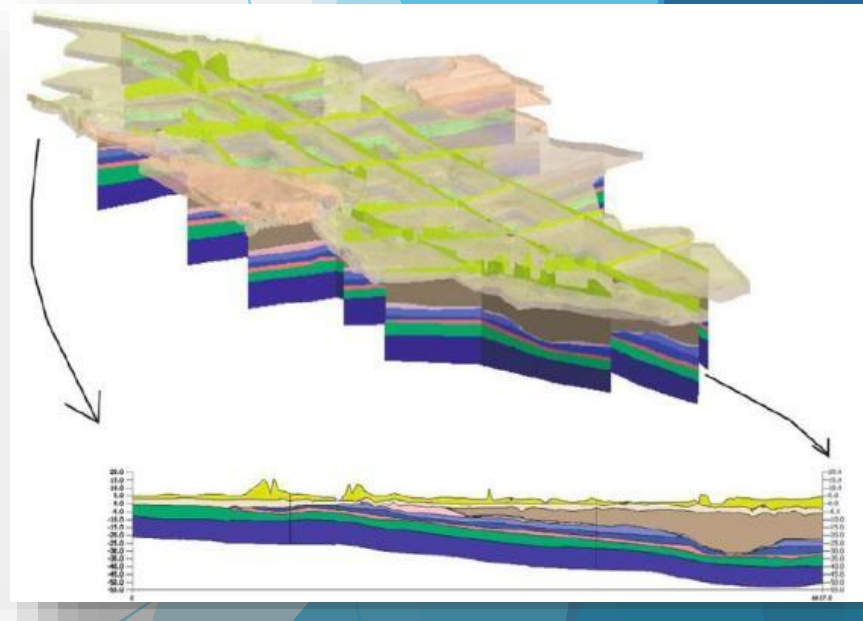

- We are open to cooperation with research institutions and government agencies worldwide. 
